\title{
Genotoxicity of quinolone antibiotics in chlorination disinfection treatment: formation and QSAR simulation
}

\author{
$\operatorname{Min} \mathrm{Li}^{1,2,3} \cdot$ Dongbin Wei ${ }^{1,2} \cdot$ Yuguo $\mathrm{Du}^{1,2}$
}

Received: 19 April 2016 / Accepted: 13 July 2016 /Published online: 28 July 2016

(C) Springer-Verlag Berlin Heidelberg 2016

\begin{abstract}
Lots of unexpected disinfection by-products were formed during the chlorination disinfection of contaminated water bodies, leading to a potential threat to human health and ecological safety. In this study, SOS/umu assay was used to trace the genotoxicity variation of 20 quinolone compounds during the chlorination disinfection. Furthermore, two- and three-dimensional quantitative structure-activity relationship models were developed based on the electronic and hydrophobic properties of the quinolones, which were used to quantify the impact of the different structural features of the compounds on their genotoxicity variation. The results revealed that quinolones bearing hydrophilic substituents with less $\mathrm{H}$ bond donors and negative charge at the 1-position of the quinolone ring exhibited a positive correlation with genotoxicity elevation. More notably, the chlorination of quinolones in both ultrapure water and secondary effluent matrices provided comparable levels of genotoxicity, indicating that our research
\end{abstract}

Responsible editor: Marcus Schulz

Electronic supplementary material The online version of this article (doi:10.1007/s11356-016-7246-4) contains supplementary material, which is available to authorized users.

Dongbin Wei

weidb@ rcees.ac.cn

1 State Key Laboratory of Environmental Chemistry and Ecotoxicology, Research Center for Eco-Environmental Sciences, Chinese Academy of Sciences, Beijing 100085, People's Republic of China

2 University of Chinese Academy of Sciences, Beijing 100049, People's Republic of China

3 College of Biological Science and Engineering, Beifang University of Nationalities, Yinchuan 750021, Ningxia Province, People's Republic of China could potentially be used to evaluate the environmental risk of quinolone antibiotics in chlorination disinfection treatment.

Keywords Quinolone · Chlorination · Disinfection ·

Genotoxicity $\cdot$ QSAR $\cdot$ CoMSIA

$\begin{array}{ll}\text { Abbreviations } \\ \text { STPs } & \text { Sewage treatment plants } \\ \text { FAC } & \text { Free available chlorine } \\ \text { DBPs } & \text { Disinfection by-products } \\ \text { DMSO } & \text { Dimethyl sulfoxide } \\ \text { 4-NQO } & \text { 4-Nitroquinoline- } N \text {-oxide } \\ \text { GeF } & \text { Genotoxicity formation } \\ \text { CoMFA } & \text { Comparative molecular field analysis } \\ \text { CoMSIA } & \text { Comparative molecular similarity index analysis } \\ \text { PLS } & \text { Partial least squares procedure } \\ \text { LOO } & \text { Leave-one-out procedure } \\ Q^{2} & \text { Cross-validated correlation coefficient } \\ N & \text { Optimal number of components } \\ R^{2} & \text { Correlation coefficient } \\ S E E & \text { Standard error of estimate } \\ F & \text { Fisher test value } \\ M & \text { Dipole moment of each molecule } \\ P S A & \text { The polar surface area }\end{array}$

\section{Introduction}

Quinolones are an important class of synthetic antibiotics, which have been used extensively during the last few decades for the treatment of a range of diseases in both humans and animals. Significant quantities of quinolones have consequently entered directly or indirectly into the environment via a multitude of different pathways. Tens of quinolones have 
been found in variety of different environmental matrices, including surface water (Kolpin et al. 2002; Kim et al. 2009; Li et al. 2012; Bu et al. 2013), as well as municipal sewage and hospital wastewater (Hartmann et al. 1998; Thomas et al. 2007; Seifrtova et al. 2008). For example, a total of 118 pharmaceuticals have been observed in urban wastewater samples, with ciprofloxacin and ofloxacin being the most frequently detected of these compounds at concentrations as high as 14 and $32 \mu \mathrm{g} / \mathrm{L}$, respectively (Verlicchi et al. 2012). Quinolones have also been detected following secondary biological treatment processes because of incomplete elimination during the treatment of the wastewater, with the residual levels of ciprofloxacin in secondary effluents ranging from 0.13 to $0.64 \mu \mathrm{g}$ /L (Golet et al. 2003; Costanzo et al. 2005; Watkinson et al. 2007). It has been reported that the total concentration of detectable quinolones could reach $1.01 \pm 0.22 \mu \mathrm{g} / \mathrm{L}$ in the secondary effluents from Chinese sewage treatment plants (STPs) (Jia et al. 2012). The occurrence of quinolones in these aquatic environments has raised particular concern because of their long-term input, low susceptibility to biodegradation, and the formation of antimicrobial resistance (Harris et al. 2012; Johnning et al. 2015; Xu et al. 2015; Bajaj et al. 2016; Varela et al. 2016). Furthermore, quinolones have been reported to exhibit significant genotoxic and mutagenic potential toward a large proportion of the bacteria against which they have been tested (Mamber et al. 1993; Hartmann et al. 1998; Hu et al. 2007; Khadra et al. 2012; Li et al. 2014). Since most quinolones in the aquatic environment are released from the effluents of municipal STPs, the removal efficiency of quinolone antibiotics in STPs plays a crucial role in controlling their role as pollutants (Jia et al. 2012).

The shortage of freshwater resources represents a growing problem in many countries throughout the world, as existing supply routes continue to be stretched by population growth and economic development. Extensive practical experience has shown that wastewater reclamation and reuse represents a feasible and attractive way to relieve issues surrounding the supply of freshwater (Asano 1996; Chu et al. 2004). Conven tional secondary treatment, however, cannot remove all the chemical and pathogenic contaminants present in wastewater, except for some advanced treatment techniques (Niu et al. 2012; Mahdi-Ahmed and Chiron 2014). A disinfection process is required to guarantee the safety and quality of the water, and this practice applies not only to conventional secondary treatment but also to reclamation treatment. Free available chlorine (FAC) has been used extensively as a disinfectant for reducing pathogenic risk because of its strong oxidation potential. Some organic and inorganic substances in wastewater, however, can react with FAC to generate toxic disinfection by-products (DBPs) (Ashbolt 2004), resulting in adverse impact on human health and ecological safety. Several antibiotics by chlorination has been reported in the literature with respect to their removal efficiencies and transformation pathways (Dodd et al. 2004; Dodd et al. 2005; Li and Zhang 2012; El Najjar et al. 2013). It is currently not possible to detect all of the toxic DBPs individually even with advanced monitoring techniques, and the biological effects have consequently been used as an alternative way to represent the formation of toxic DBPs as a whole following the chlorination process (Wang et al. 2007a).

The short-term SOS/umu test is based on the ability of genotoxic agents to induce the expression of the umuC-gene in response to genotoxic lesions in the DNA (ISO 2000). Reifferscheid and Heil (1996) demonstrated that the SOS/ umu test can be used as an important and reliable tool for the assessment of a compound's genotoxicity and reported a concordance of approximately $90 \%$ with the Ames test. The SOS/umu test is particularly useful for determining the umuCdependent mutagenic potentials of chemicals in the context of environmental pollution. The purpose of the current study is to measure the genotoxicity variation of chlorination systems containing quinolones using SOS/umu test. Previous studies in this area have indicated that the chemical substituents on the quinolone ring impacted not only the potency and spectrum of the antibacterial activities of these compounds (Domagala 1994) but also the primary active sites during the chemical reactions (Zhang and Huang 2005; De Witte et al. 2009; Li et al. 2011). Furthermore, the quinolone skeleton remains intact during the chlorination process (Dodd et al. 2005; El Najjar et al. 2013). Based on these observations, it is reasonable to assume that the differences in the genotoxicity of the compounds formed during the chlorination disinfection process are dependent on the chemical substituents on the quinolone ring. With this in mind, the quantitative structureactivity relationship (QSAR) techniques could be applied to explore the relationship between the different substituents on the quinolone ring and their genotoxicity during the chlorination process. The results of the current study could be used to provide useful information for evaluating the potential environmental risk associated with the chlorination of quinolones.

\section{Materials and methods}

\section{Reagents and solutions}

The 20 quinolone antibiotics used in the current study are listed in Fig. S1. These compounds were purchased from Sigma-Aldrich (St Louis, MO, USA) and the National Insti tute for Food and Drug Control of China (Beijing, China). All of the reagents were purchased as reagent grade (purity $>97 \%$ ) and used directly without purification. Stock solutions of the quinolones were prepared in ultrapure water, which was produced using a Milli-Q ultrapure water system (Millipore, Billerica, MA, USA). 


\section{Chlorination disinfection treatment}

Considering the residual level of quinolones in secondary effluent of STPs (ca. $\mu \mathrm{g} / \mathrm{L}$ level), and the operating parameters required for a practical chlorination disinfection treatment process (i.e., $0.3-22 \mathrm{mg} / \mathrm{L}$ FAC dose and 30-60 min retention time) (Krasner et al. 2009), the chlorination reaction was set up as follows: Each of the quinolone stock solution was diluted by phosphate buffer solution $(0.02 \mathrm{M}, \mathrm{pH}$ 7) to prepare working solution $(1.0-1.0 \mathrm{mM})$, and the dilution rate reached to 100 times at least. Then, the working solution was placed into a $200-\mathrm{mL}$ amber borosilicate glass bottle, and 10 equivalents of FAC was added to trigger reaction, the mixed solution kept constant stirring at $25^{\circ} \mathrm{C}$ over a period of $60 \mathrm{~min}$. Phosphate buffer solution $(0.02 \mathrm{M})$ was used to maintain the reaction at $\mathrm{pH} 7$. The reaction was quenched with $1 \mathrm{M}$ sodium sulfite solution, freeze-dried, and extracted with a 1:1 $(v / v)$ mixture of methanol/acetone $(10 \mathrm{~mL})$. The supernatant was collected and dried under a stream of $\mathrm{N}_{2}$ to give a residue, which was dissolved in dimethyl sulfoxide (DMSO) prior to being tested for its genotoxicity. The chlorination experiment was conducted in triplicate for each quinolone compound.

\section{Chlorination treatment on secondary effluents}

Two secondary effluent samples were collected from two different STPs in Beijing, China. The physicochemical properties of the two water samples were analyzed in accordance with standard methods (APHA 1998). To effectively simulate the chlorination conditions used in conventional disinfection processes in STPs, four quinolones were randomly selected as targets to respectively perform chlorination treatment in two secondary effluents with the following operating parameters:
$20 \mathrm{~mL}$ of each effluent sample was spiked with $0.56-1.12 \mathrm{mg} /$ $\mathrm{L}(0.0028 \mathrm{mM})$ of the quinolones and $2 \mathrm{mg} / \mathrm{L}(0.028 \mathrm{mM})$ of FAC (about 10 equivalents to quinolones), and the resulting mixture was agitated for $60 \mathrm{~min}$. All of the water samples were treated directly without adjusting their $\mathrm{pH}$ conditions. The water samples were then subjected to the treatment method described above in "Chlorination disinfection treatment" section. The chlorination treatment of each targeted quinolone compound in both secondary effluent matrices was conducted in duplicate.

\section{Genotoxicity assay}

The SOS/umu assay for short-term genotoxicity screening was carried out according to the standard ISO protocol (Oda et al. 1985; ISO 2000). The test Salmonella typhimurium TA1535/pSK1002 was donated by Professor Oda (Japan). Each extracted sample from the previous chlorination treatment was challenged with $S$. typhimurium in triplicate. For each test, a series of 4-nitroquinoline- $N$-oxide (4-NQO) solutions were set as positive controls to obtain a dose-response curve. The genotoxicity of each sample was converted to its equivalent value relative to the 4-NQO reference, and the values are shown in the Supplementary Data (Table S1). The exposure concentration of DMSO, which was used as a cosolvent for evaluating the genotoxicities of the samples, was set at $0.1 \%(v / v)$. The genotoxicity changes of samples collected prior to chlorination after quinolone compounds spiked in and samples collected at the end of chlorination treatment were determined. And an index defined as genotoxicity formation $(\mathrm{GeF})$ was proposed to describe the genotoxicity changes quantificationally. Taking ofloxacin as an example, the $G e F_{o f l o x a c i n}$ value can be defined as follows

$G e F_{\text {ofloxacin }}=$ the genotoxicity value after chlorination/genotoxicity value before chlorination

Using this equation, a $\log G e F$ value greater than zero indicates an increase in the genotoxicity during the chlorination treatment, whereas a $\log G e F$ value of less than zero indicates a decrease in the genotoxicity. Furthermore, the higher the $\log G e F$ value, the greater the genotoxicity following the chlorination treatment process. Details of the calculation methods used to determine the $\log G e F$ values have been provided in the Text S1 and Fig. S2.

\section{D-QSAR method}

The molecule structure descriptors for the quinolones used in the current study were obtained using the ADRIANA. Code program (Ver2.2.4, Molecular Networks GmbH, Germany). A total of $1552 \mathrm{D}$ descriptors were calculated for the quinolones to provide an adequate representation of their shape, topological and global molecular properties. All of the descriptors were selected as independent variables, whereas the $\log G e F$ values were selected as dependent variables. A stepwise multiple linear regression method was used to establish the fitting models.

\section{D-QSAR method}

All of the molecular modeling techniques and 3D-QSAR analyses were performed using version 8.0 of the SYBYL software (Tripos Inc., USA). The structures of the 20 quinolones used in the current study were fully geometry-optimized using the Tripos force field. An energy gradient convergence criterion of $0.005 \mathrm{Kcal} / \mathrm{mol} / \AA$ was used to achieve energy 
minimization. Partial atomic charges were assigned using the Gasteiger-Hückel formation to calculate the electrostatic potential. Ofloxacin, which displayed the most significant changes in its genotoxicity, was selected as the template molecule. All of the other molecules were superimposed onto OFL according to the database alignment rules, and a $3 \mathrm{D}$ view of the aligned molecules is shown in Fig. S3.

The overlapped molecules were placed in a $3 \mathrm{D}$ cubic lattice with a $2-\AA$ grid (Lu et al. 2010). For the comparative molecular field analysis (CoMFA) model, the steric and electrostatic fields were calculated using a standard Tripos force field. An $\mathrm{sp}^{3}$ carbon atom with a charge of +1.0 was used as a probe to generate the energies of the steric and electrostatic fields. A default energy value of $30 \mathrm{kcal} / \mathrm{mol}$ was used to avoid an infinity of energy values inside the molecules. The comparative molecular similarity index analysis (CoMSIA) model was generated based on the same lattice box. Given that this model represents an extension to the CoMFA approach, five fields, including steric, electrostatic, hydrophobic, H-bond donor, and acceptor fields, were calculated using the standard settings (Klebe and Abraham 1999; Hou and Xu 2001).

Statistical analysis was performed using the partial least squares (PLS) procedure, and cross-validation was achieved by the leave-one-out (LOO) procedure. The cross-validated correlation coefficient $\left(Q^{2}\right)$ allows for the predictive capacity of the model to be quantified and should be greater than 0.5 . The optimal number of components $(N)$ was employed to allow for the validation of the PLS analysis, generate the final model, and derive a contour map. The correlation coefficient $R^{2}$ was used to represent the self-consistency of the model and should be greater than 0.9. The standard error of estimate (SEE) and the Fisher test $(F)$ values were also calculated.

\section{Results and discussion}

The genotoxicity variation of the 20 quinolones during the chlorination disinfection process was determined using SOS/umu assay, and their $\log G e F$ values are shown in Table 1 . The results revealed that the majority of the compounds tested exhibited low $\log G e F$ values, although several compounds with complex structures did give relatively high $\log G e F$ values following the chlorination process.

\section{D-QSAR analysis}

A statistical model involving the $\log G e F$ values and the physicochemical descriptors was obtained using a stepwise multiple linear regression analysis. This process can be described as follows:

$$
\log \mathrm{GeF}=14.10( \pm 2.62)-0.41( \pm 0.14)
$$

$$
\begin{aligned}
& \times \mu-12.36( \pm 1.99) \times R_{\text {complexity }} \\
& +1.98( \pm 0.57) \times q^{-}+0.03( \pm 0.01) \times P S A(2)
\end{aligned}
$$

$N=20, R^{2}=0.84, R_{a d j}^{2}=0.80, S E=0.60, F=20.03$, $p<0.001$

where $N$ represents the number of compounds, $R^{2}$ is the multiple correlation coefficient, $R^{2}$ adj is the multiple correlation coefficient adjusted by the degree of freedom, SE is the standard error, $F$ is the $F$-test value for the analysis of the variables, and $p$ is the significance. A plot of the observed versus the calculated $\log \mathrm{GeF}$ values is shown in Fig. 1.

The dipole moment $(\mu)$ of each molecule, which describes the net polarity and represents the charge separation in the molecule, contributes a negative contribution to the $\log \mathrm{GeF}$ value. The dipole moments of the quinolone molecules can be attributed to the carbonyl groups $\left(\mathrm{C}^{+}-\mathrm{O}^{-}\right)$at the 3- and 4positions of the quinolone ring. The carbonyl groups of the quinolone molecules can also result in permanent polarization, which can lead to a dipole-dipole-type interaction between two or more molecules through hydrogen-bonding interactions (Pillai et al. 2005). The descriptor $R_{\text {complexity }}$ represents the ring complexity proposed by Gasteiger and Jochum (1979) and reflects the significant impact of the substituents on the properties of the ring. The descriptor $q^{-}$represents the most negative atomic charge in the molecule. The polar surface area (PSA) of a molecule is defined as the sum surface area over all of the polar atoms (primarily oxygen and nitrogen atoms as well as their attached hydrogen atoms) (Ertl et al. 2000).

The descriptors involved in Eq. (1) can be divided into two different types. The first type, including $q^{-}$, is used to describe the electronic properties of the molecule. The second type, including $\mu, R_{\text {complexity, }}$ and PSA, is used to describe the hydrophobic properties of the molecule. Both types of descriptors made a significant contribution to changes in the geno toxicity of the quinolones following chlorination. The specific contributions of the different substituents of the quinolone ring on the $\log \mathrm{GeF}$ values following the chlorination process, in terms of their properties and positions, however, remain unclear. 3D-QSAR methods (using CoMFA and CoMSIA methods) can be used to complement 2D-QSAR methods and can deliver significant improvements in terms of the interpretation of the model.

\section{D-QSAR analyses}

\section{CoMFA and CoMSIA statistical results}

The statistical results of the CoMFA model are shown in Table 2. Leave-one-out analysis gave a cross-validated $Q^{2}$ value of 0.58 for three optimal components. The correlation 
Table 1 Physiochemical properties of 20 quinolones and their genotoxicity formation values in chlorination $(\log G e F)$ involved in the 2D- and 3DQSAR models

\begin{tabular}{|c|c|c|c|c|c|c|c|c|c|}
\hline \multirow[b]{2}{*}{ No. } & \multirow[b]{2}{*}{$\begin{array}{l}\log G e F \\
\text { (Ex- } \\
\text { p.) }\end{array}$} & \multicolumn{6}{|c|}{ 2D-QSAR } & \multicolumn{2}{|c|}{ 3D-CoMSIA(2) } \\
\hline & & $\mu(\mathrm{D})$ & Rcom. & $q-$ & $P S A$ & $\begin{array}{r}\log G e F \\
\text { (Cal.) }\end{array}$ & Res. & $\begin{array}{r}\log G e F \\
\text { (Cal.) }\end{array}$ & Res. \\
\hline Balofloxacin & -1.06 & 7.220 & 1.125 & -0.630 & 100.700 & -0.72 & -0.34 & -1.14 & 0.08 \\
\hline Ciprofloxacin & -1.00 & 8.598 & 1.105 & -0.615 & 86.600 & -1.47 & 0.48 & -1.19 & 0.2 \\
\hline Danofloxacin & -3.01 & 9.245 & 1.211 & -0.622 & 76.500 & -3.39 & 0.38 & -2.97 & -0.04 \\
\hline Difloxacin & -1.09 & 7.240 & 1.091 & -0.626 & 76.500 & -1.09 & 0 & -1.11 & 0.02 \\
\hline Enrofloxacin & -2.89 & 9.515 & 1.105 & -0.616 & 76.500 & -2.18 & -0.7 & -2.80 & -0.08 \\
\hline Fleroxacin & -1.97 & 6.386 & 1.125 & -0.626 & 76.500 & -1.16 & -0.81 & -2.11 & 0.14 \\
\hline Gatifloxacin & -1.36 & 9.102 & 1.105 & -0.627 & 100.700 & -1.24 & -0.12 & -1.43 & 0.07 \\
\hline Levofloxacin & -3.78 & 8.843 & 1.263 & -0.628 & 90.600 & -3.42 & -0.35 & -3.90 & 0.13 \\
\hline Lomefloxacin & -1.38 & 7.798 & 1.125 & -0.621 & 86.600 & -1.4 & 0.02 & -1.28 & -0.1 \\
\hline Nadifloxacin & -1.75 & 7.871 & 1.263 & -0.629 & 97.600 & -2.8 & 1.05 & -1.76 & 0.01 \\
\hline Norfloxacin & -1.14 & 8.675 & 1.125 & -0.622 & 86.600 & -1.76 & 0.62 & -1.36 & 0.22 \\
\hline Ofloxacin & -3.97 & 8.843 & 1.263 & -0.625 & 90.600 & -3.41 & -0.56 & -3.90 & -0.07 \\
\hline Pazufloxacin & -3.83 & 8.300 & 1.313 & -0.634 & 108.100 & -3.25 & -0.58 & -3.87 & 0.04 \\
\hline Pefloxacin & -3.08 & 9.614 & 1.125 & -0.635 & 76.500 & -2.5 & -0.57 & -2.86 & -0.21 \\
\hline Rufloxacin & -3.23 & 8.794 & 1.263 & -0.621 & 76.500 & -3.84 & 0.62 & -3.08 & -0.14 \\
\hline Sarafloxacin & 0.23 & 6.261 & 1.091 & -0.626 & 86.600 & -0.36 & 0.59 & 0.38 & -0.15 \\
\hline Sparfloxacin & 0.11 & 6.805 & 1.105 & -0.608 & 109.500 & 0.028 & 0.082 & 0.21 & -0.1 \\
\hline Cinoxacin $^{\mathrm{a}}$ & -0.43 & 7.792 & 1.308 & 0.619 & 110.600 & -0.41 & -0.02 & & \\
\hline Enoxacin $^{\mathrm{a}}$ & -0.83 & 9.220 & 1.105 & -0.613 & 97.900 & -1.35 & 0.52 & & \\
\hline $\begin{array}{l}\text { Pipemidic } \\
\text { acid }^{\mathrm{a}}\end{array}$ & -0.50 & 6.606 & 1.125 & -0.630 & 109.200 & -0.19 & -0.31 & & \\
\hline
\end{tabular}

All compounds were used as the training set in the 2D-QSAR

$\mu$ dipole moment in Debye, Rcom. $R_{\text {compolexity }} q^{-}$most negative atomic charge in the solution molecule, PSA polar surface area, Exp. experimental (actual) value, Cal. calculated value from QSAR models, Res. residue between the experimental and calculated values

${ }^{\text {a }}$ Rejected compounds to 3D-QSAR because of their naphthyridone core coefficient $R^{2}$ was determined to be 0.97 for the non-crossvalidated PLS analysis. The correlation between the observed and calculated values is shown in Fig. 1, and the steric and electrostatic contour maps are shown in Fig. S4.

The results of CoMSIA(1) are shown in Table 2 and revealed that the H-bond donor, hydrophobic, and electrostatic fields made the greatest contribution to the $\log G e F$ value, whereas the steric and H-bond acceptor fields made a much smaller contribution. Based on these results, we constructed a second CoMSIA model known as CoMSIA(2), which excluded the steric and H-bond acceptor fields. A cross-validated $Q^{2}$ value of 0.69 was obtained with five optimal components, together with an $R^{2}$ value of 0.99 . The $F$ and $S E$ values were 242.81 and 0.15 , respectively. A plot of the observed values
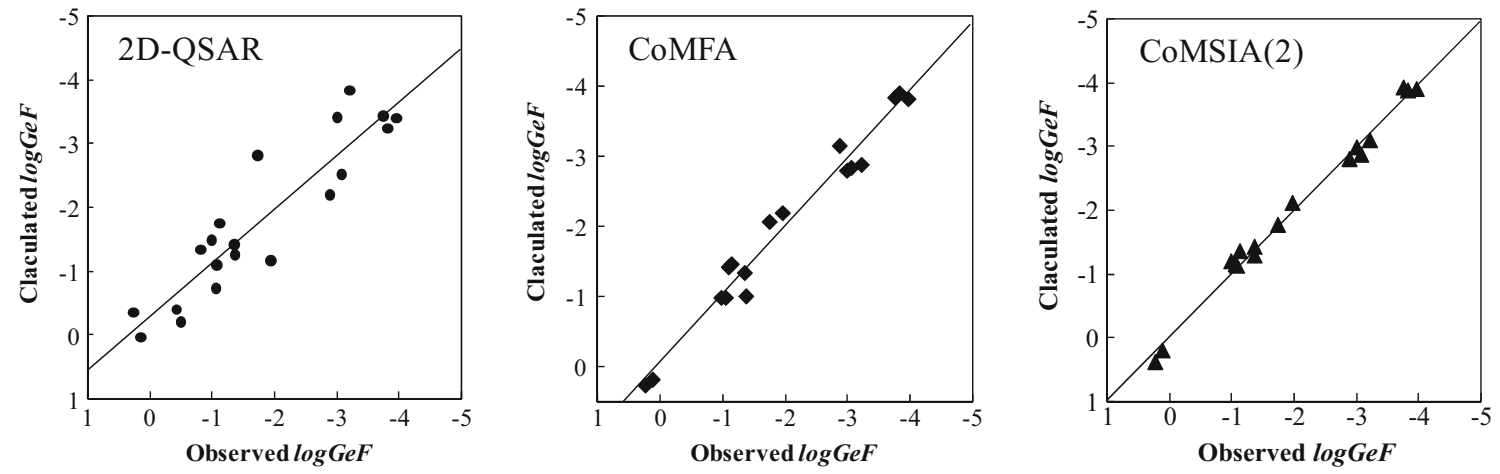

Fig. 1 Plot of observed vs calculated values for QSAR models 
Table 2 Summary of 3D-QSAR models

\begin{tabular}{|c|c|c|c|c|c|c|c|c|c|c|}
\hline \multirow[t]{2}{*}{ Model } & \multirow[t]{2}{*}{$Q^{2}$} & \multirow[t]{2}{*}{$R^{2}$} & \multirow[t]{2}{*}{$S E$} & \multirow[t]{2}{*}{$F$} & \multirow[t]{2}{*}{$N C$} & \multicolumn{5}{|c|}{ Contribution } \\
\hline & & & & & & $\mathrm{S}^{\mathrm{a}}$ & $E^{b}$ & $\mathrm{H}^{\mathrm{c}}$ & $\mathrm{D}^{\mathrm{d}}$ & $\mathrm{A}^{\mathrm{e}}$ \\
\hline CoMFA & 0.58 & 0.97 & 0.26 & 139.41 & 3 & 0.749 & 0.251 & & & \\
\hline CoMSIA(1) & 0.66 & 0.98 & 0.18 & 223.91 & 4 & 0.062 & 0.148 & 0.301 & 0.463 & 0.026 \\
\hline CoMSIA(2) & 0.69 & 0.99 & 0.15 & 242.81 & 5 & & 0.177 & 0.342 & 0.481 & \\
\hline
\end{tabular}

${ }^{\mathrm{a}}$ Steric field

${ }^{\mathrm{b}}$ Electrostatic field

${ }^{\mathrm{c}}$ Hydrophobic field

${ }^{\mathrm{d}} \mathrm{H}$-bond donor field

${ }^{\mathrm{e}} \mathrm{H}$-bond accept field

versus the calculated values is shown in Fig. 1. Statistical analysis of this model revealed that a reliable CoMSIA(2) model had been successfully developed.

\section{Interpretation of CoMISA(2) contour maps}

An electrostatic contour map of the CoMSIA(2) model is shown in Fig. 2a. The red contours represent the negatively charged areas of the molecule that favored an increase in genotoxicity, and the blue contours represent the positively charged areas of the molecule that favored an increase in the genotoxicity. A large red contour surrounded the 1-position of the quinolone ring, indicating that substituents bearing negative charge in this region would afford a high level of genotoxicity. This result was supported by sarafloxacin (bearing a strong electron-withdrawing $p$-fluorophenyl group at the 1-position), which had a higher $\log G e F$ value than those of norfloxacin and ciprofloxacin (bearing electron-donating eth$\mathrm{yl}$ and cyclopropyl groups at the 1-position, respectively).

The hydrophobic contour map is depicted in Fig. 2b. The yellow and white colored regions of the contour map represent the areas of the quinolone ring that favor hydrophobic and hydrophilic groups, respectively. A large white area surroun ded the 7-position, which suggested that the introduction of hydrophilic substituents at this position would lead to a significant increase in the genotoxicity of the compounds following the chlorination treatment. This result was in agreement with the steric map provided by the CoMFA model (Fig. S4a),
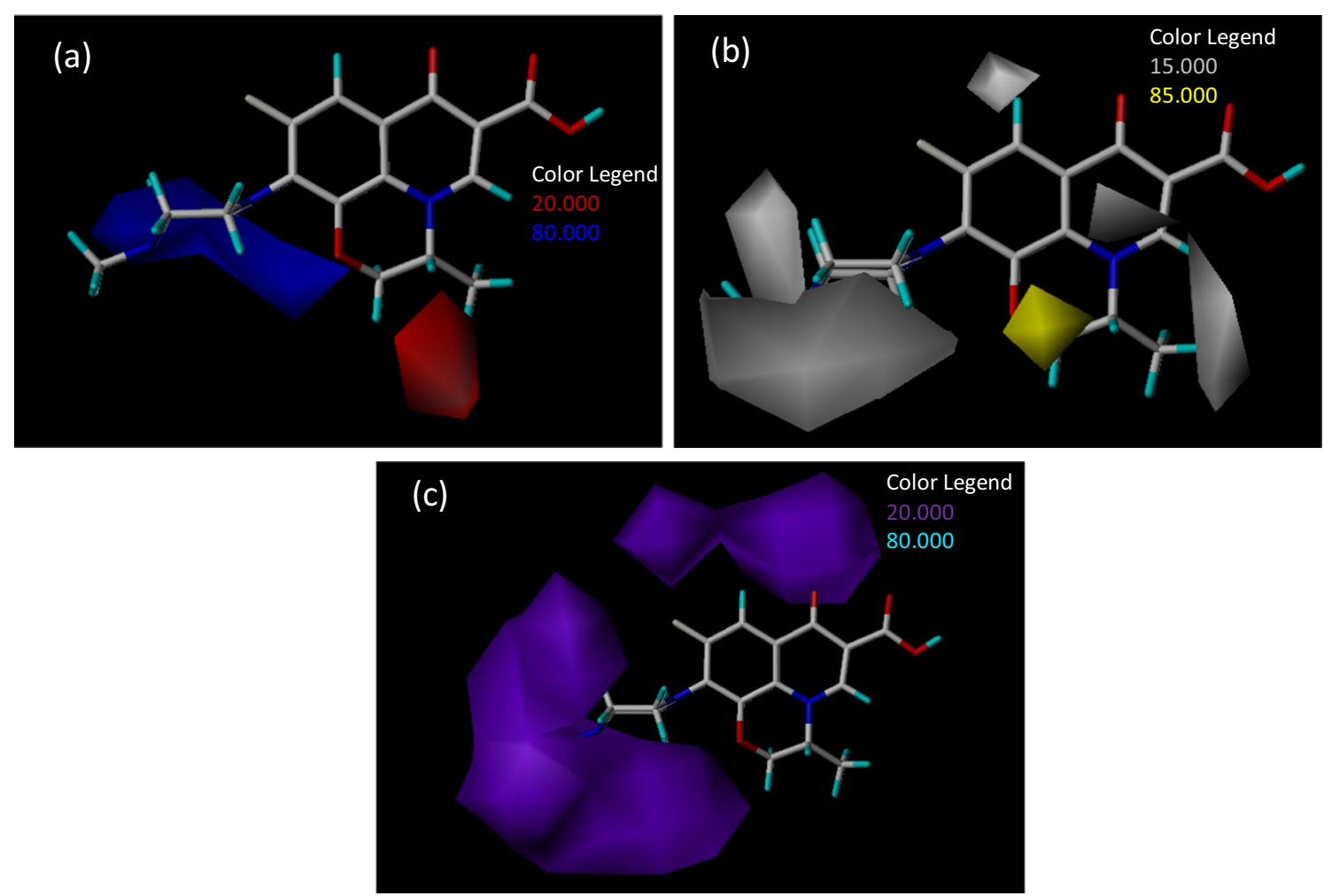

Fig. 2 Contour maps for CoMSIA(2) model. a Electrostatic field. b Hydrophobic field. c H-donor field 
Table 3 Parameters of two secondary effluents samples

\begin{tabular}{lllllll}
\hline & $\mathrm{pH}$ & $\mathrm{NH}_{3}-\mathrm{N}(\mathrm{mg} / \mathrm{L})$ & $\mathrm{COD}(\mathrm{mg} / \mathrm{L})$ & $\mathrm{DOC}(\mathrm{mg} / \mathrm{L})$ & $\mathrm{UV}_{254}(/ \mathrm{cm})$ & Gene toxic $^{\mathrm{a}}$ \\
\hline $1 \#$ & 6.75 & 2.28 & 8.37 & 2.30 & 0.128 & no \\
$2 \#$ & 8.67 & 6.85 & 11.16 & 3.94 & 0.140 & no \\
\hline
\end{tabular}

${ }^{\text {a }}$ Gene toxic effect was tested with SOS/umu assay in that small groups at the 7-position favored high levels of genotoxicity. Variations in the $\log G e F$ values of the quinolones could be attributed to the hydrophilicity of the substituent at the 7-position. Quinolones bearing an $N$-methylated piperazine group exhibited lower levels of both hydrophilicity and genotoxicity, as evidenced by the compound pairs sara floxacin/difloxacin, ciprofloxacin/enrofloxacin, and nor floxacin/pefloxacin (Fig. S1). This result correlated well with the positive contribution of the polar surface area descriptor in the 2D-QSAR model.

The H-bond donor properties are shown in Fig. 2c. The cyan contours represent the regions of the quinolone structure where the introduction of hydrogen bond donating substituents led to an increase in the genotoxicity, and the purple contours represent areas where the inclusion of hydrogen bond donating substituents led to a decrease in the genotoxi city. A large purple contour appeared in the region where the H-bond donors derived from amine groups made a negative contribution on the genotoxicity.

\section{Validation of genotoxicity formation in secondary effluent matrices}

To determine whether similar genotoxicity patterns would be observed following the conventional chlorination process, four quinolones were randomly selected and subjected to the two secondary effluents from two STPs, Beijing. The physicochemical characteristics of those two secondary effluents \#1 and \#2 are listed in Table 3. The $\log G e F$ values of the four quinolones measured in the two secondary effluents as well as

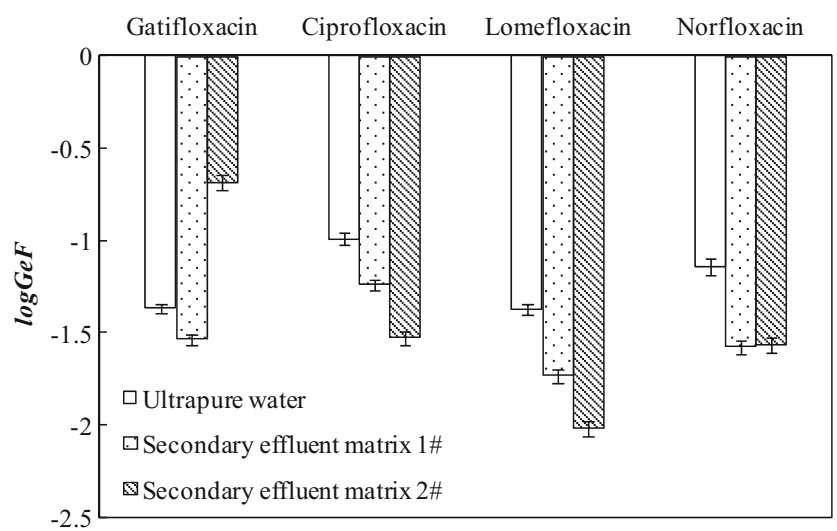

Fig. 3 Genotoxicity formation values $(\log G e F)$ of quinolones in different matrices ultrapure water system are shown in Fig. 3. In the two secondary effluents, the $\log G e F$ values of three quinolones were slightly reduced, except for gatifloxacin in secondary effluent \#2. Using two secondary effluents as controls for umu/SOS toxicity test, parameters of dissolvable organic carbon levels and $\mathrm{UV}_{254}$ spectrum (Li et al. 2000) were excluded, and ammonia nitrogen $\left(\mathrm{NH}_{3}-\mathrm{N}\right)$ was identified as a critical parameter accounts for the decrease of $\log \mathrm{GeF}$ values. It was envisaged that the $\mathrm{NH}_{3}-\mathrm{N}$ consumed FAC quickly (Qiang and Adams 2004), leading to the formation of inactive chloramine, which would in turn lead to a reduction in the formation of toxic byproducts in most cases (Wang et al. 2007b).

\section{Environmental implication}

Previous work in this area implied that the antibacterial activities of quinolones could be retained even after the chlorination disinfection process. This retention of activity was attributed to the quinolone skeleton remaining intact through the chlorination process, although the corresponding biological data has not been reported (Dodd et al. 2005). With respect to 18 of the quinolones investigated in the current study, $\mathrm{Hu}$ et al. (2007) reported a negative relationship between the minimum inhibitory concentrations $\left(\mathrm{MIC}_{50}\right)$ of these compounds against Streptococcus pneumoniae and their genotoxic potentials (based on the SOS/umu assay). The results of the current study indicated that the genotoxic potentials of most of the quinolone derivatives were reduced significantly following the chlorination disinfection treatment and gave low antibacterial activities. This result suggested that the chlorination disinfection of quinolone-containing wastewater would not only decrease the potential risk but also eliminate the occurrence of drug resistance in bacterial pathogens.

\section{Conclusions}

The genotoxicity of 20 quinolones formed in chlorination disinfection treatment was measured using the SOS/umu assay, and an index of genotoxicity formation $(\mathrm{GeF})$ was used to evaluate the genotoxicity changes of the compounds. 2Dand 3D-QSAR models were established to estimate the contributions of the different chemical substituents on the quinolone skeleton to the genotoxicity. These models suggested that the presence of hydrophilic substituents containing less $\mathrm{H}$ - 
bond donors or negative charge at the 1-position of the quinolone ring would lead to an increase in the genotoxicity after the chlorination process. Furthermore, the result was successfully applied to secondary effluents of STPs, and the present research implied that the chlorination disinfection treatment of quinolone-containing wastewater could potentially reduce its ecological impact.

Acknowledgments This work was financially supported by the National Natural Science Foundation of China (Grant Nos. 21377143, 21577154, and 21590814). We are grateful to Prof. Aixia Yan and Dr. Jiaxuan Li from the University of Beijing Chemical Technology for their assistance with the QSAR calculations.

\section{References}

APHA (1998) Standard methods for the examination of water and wastewater (20th ed.). American Public Health Association, New York, USA

Asano T, Levine AD (1996) Wastewater reclamation, recycling and reuse: past, present, and future. Water Sci Technol 33:1-14

Ashbolt NJ (2004) Risk analysis of drinking water microbial contamination versus disinfection by-products (DBPs). Toxicology 198:255-262

Bajaj P, Kanaujia PK, Singh NS, Sharma S, Kumar S, Virdi JS (2016) Quinolone co-resistance in ESBL- or AmpC-producing Escherichia coli from an Indian urban aquatic environment and their public health implications. Environ Sci Pollut Res 23:1954-1959

Bu QW, Wang B, Huang J, Deng SB, Yu G (2013) Pharmaceuticals and personal care products in the aquatic environment in China: a review. J Hazard Mater 262:189-211

Chu JY, Chen JN, Wang C, Fu P (2004) Wastewater reuse potential analysis: implications for China's water resources management. Water Res 38:2746-2756

Costanzo SD, Murby J, Bates J (2005) Ecosystem response to antibiotics entering the aquatic environment. Mar Pollut Bull 51:218-223

De Witte B, Van Langenhove H, Hemelsoet K, Demeestere K, De Wispelaere P, Van Speybroeck V, Dewulf J (2009) Levofloxacin ozonation in water: rate determining process parameters and reaction pathway elucidation. Chemosphere 76:683-689

Dodd MC, Huang CH (2004) Transformation of the antibacterial agent sulfamethoxazole in reactions with chlorine: kinetics mechanisms, and pathways. Environmental Science \& Technology 38:56075615

Dodd MC, Shah AD, Von Gunten U, Huang CH (2005) Interactions of fluoroquinolone antibacterial agents with aqueous chlorine: reaction kinetics, mechanisms, and transformation pathways. Environmental Science \& Technology 39:7065-7076

Domagala JM (1994) Structure-activity and structure-side-effect relationships for the quinolone antibacterials. J Antimicrob Chemother 33: 685-706

El Najjar NH, Deborde M, Journel R, Vel Leitner NK (2013) Aqueous chlorination of levofloxacin: kinetic and mechanistic study, transformation product identification and toxicity. Water Res 47:121-129

Ertl P, Rohde B, Selzer P (2000) Fast calculation of molecular polar surface area as a sum of fragment-based contributions and its application to the prediction of drug transport properties. J Med Chem 43: 3714-3717

Gasteiger J, Jochum C (1979) An algorithm for the perception of synthetically important rings. J Chem Inf Comput Sci 19:43-48
Golet EM, Xifra I, Siegrist H, Alder AC, Giger W (2003) Environmental exposure assessment of fluoroquinolone antibacterial agents from sewage to soil. Environmental Science \& Technology 37:3243-3249

Harris SJ, Cormican M, Cummins E (2012) Antimicrobial residues and antimicrobial-resistant bacteria: impact on the microbial environment and risk to human health - a review. Hum Ecol Risk Assess 18:767-809

Hartmann A, Alder AC, Koller T, Widmer RM (1998) Identification of fluoroquinolone antibiotics as the main source of umuC genotoxicity in native hospital wastewater. Environ Toxicol Chem $17: 377-382$

Hou TJ, Xu XJ (2001) Three-dimensional quantitative structure-activity relationship analyses of a series of cinnamamides. Chemom Intell Lab Syst 56:123-132

Hu J, Wang W, Zhu Z, Chang H, Pan F, Lin B (2007) Quantitative structure-activity relationship model for prediction of genotoxic potential for quinolone antibacterials. Environmental Science \& Technology 41:4806-4812

ISO (2000) Water quality - determination of the genotoxicity of water and waste water using the umu-test. (1st ed., ISO 13829, Geneva, Switzerland), 1-18

Jia A, Wan Y, Xiao Y, Hu J (2012) Occurrence and fate of quinolone and fluoroquinolone antibiotics in a municipal sewage treatment plant. Water Res 46:387-394

Johnning A, Kristiansson E, Angelin M, Marathe N, Shouche YS, Johansson A, Larsson DGJ (2015) Quinolone resistance mutations in the faecal microbiota of Swedish travellers to India. BMC Microbiol 15:235-242

Khadra A, Pinelli E, Lacroix MZ, Bousquet-Melou A, Hamdi H, Merlina G, Guiresse M, Hafidi M (2012) Assessment of the genotoxicity of quinolone and fluoroquinolones contaminated soil with the Vicia faba micronucleus test. Ecotoxicol Environ Saf 76:187-192

Kim JW, Jang HS, Kim JG, Ishibashi H, Hirano M, Nasu K, Ichikawa N, Takao Y, Shinohara R, Arizono K (2009) Occurrence of pharmaceutical and personal care products (PPCPs) in surface water from Mankyung River, South Korea. J Health Sci 55:249-258

Klebe G, Abraham U (1999) Comparative molecular similarity index analysis (CoMSIA) to study hydrogen-bonding properties and to score combinatorial libraries. J Comput Aided Mol Des 13:1-10

Kolpin DW, Furlong ET, Meyer MT, Thurman EM, Zaugg SD, Barber LB, Buxton HT (2002) Pharmaceuticals, hormones, and other organic wastewater contaminants in US streams, 1999-2000: a national reconnaissance. Environmental Science \& Technology 36:1202-1211

Krasner SW, Westerhoff P, Chen BY, Rittmann BE, Amy G (2009) Occurrence of disinfection byproducts in United States wastewater treatment plant effluents. Environmental Science \& Technology 43: $8320-8325$

Li B, Zhang T (2012) pH significantly affects removal of trace antibiotics in chlorination of municipal wastewater. Water Res 46:3703-3713

Li CW, Benjamin MM, Korshin GV (2000) Use of UV spectroscopy to characterize the reaction between NOM and free chlorine. Environmental Science \& Technology 34:2570-2575

Li M, Wei D, Zhao H, Du Y (2014) Genotoxicity of quinolones: substituents contribution and transformation products QSAR evaluation using 2D and 3D models. Chemosphere 95:220-226

Li WH, Shi YL, Gao LH, Liu JM, Cai YQ (2012) Occurrence of antibiotics in water, sediments, aquatic plants, and animals from Baiyangdian Lake in North China. Chemosphere 89:1307-1315

Li Y, Niu JF, Wang WL (2011) Photolysis of enrofloxacin in aqueous systems under simulated sunlight irradiation: kinetics, mechanism and toxicity of photolysis products. Chemosphere 85:892-897

Lu P, Wei X, Zhang R (2010) CoMFA and CoMSIA 3D-QSAR studies on quionolone caroxylic acid derivatives inhibitors of HIV-1 integrase. Eur J Med Chem 45:3413-3419 
Mahdi-Ahmed M, Chiron S (2014) Ciprofloxacin oxidation by UV-C activated peroxymonosulfate in wastewater. J Hazard Mater 265: $41-46$

Mamber SW, Kolek B, Brookshire KW, Bonner DP, Fungtomc J (1993) Activity of quinolones in the Ames salmonella-TA102 mutagenicity test and other bacterial genotoxicity assays. Antimicrob Agents Chemother 37:213-217

Niu JF, Lin H, JL X, Wu H, Li YY (2012) Electrochemical mineralization of perfluorocarboxylic acids (PFCAs) by Ce-doped modified porous nanocrystalline $\mathrm{PbO}_{2}$ film electrode. Environmental Science \& Technology 46:10191-10198

Oda Y, Nakamura S, Oki I, Kato T, Shinagawa H (1985) QSAR studies on some thiophene analogs as anti-inflammatory agents: enhancement of activity by electronic parameters and its utilization for chemical lead optimization. Mutat Res 147:219-229

Pillai AD, Rani S, Rathod PD, Xavier FP, Vasu KK, Padh H, Sudarsanam V (2005) QSAR studies on some thiophene analogs as antiinflammatory agents: enhancement of activity by electronic parameters and its utilization for chemical lead optimization. Bioorg Med Chem 13:1275-1283

Qiang ZM, Adams CD (2004) Determination of monochloramine formation rate constants with stopped-flow spectrophotometry. Environmental Science \& Technology 38:1435-1444

Reifferscheid G, Hell J (1996) Validation of the SOS/umu test using test results of 486 chemicals and comparison with the Ames test and carcinogenicity data. Mutation Research-Genetic Toxicology 369: $129-145$

Seifrtova M, Pena A, Lino CM, Solich P (2008) Determination of fluoroquinolone antibiotics in hospital and municipal wastewaters in Coimbra by liquid chromatography with a monolithic column and fluorescence detection. Anal Bioanal Chem 391:799-805
Thomas KV, Dye C, Schlabach M, Langford KH (2007) Source to sink tracking of selected human pharmaceuticals from two Oslo city hospitals and a wastewater treatment works. J Environ Monit 9: $1410-1418$

Varela AR, Nunes OC, Manaia CM (2016) Quinolone resistant Aeromonas spp. as carriers and potential tracers of acquired antibiotic resistance in hospital and municipal wastewater. Sci Total Environ 542:665-671

Verlicchi P, Al Aukidy M, Zambello E (2012) Occurrence of pharmaceutical compounds in urban wastewater: removal, mass load and environmental risk after a secondary treatment-a review. Sci Total Environ 429:123-155

Wang LS, HY H, Wang C (2007a) Effect of ammonia nitrogen and dissolved organic matter fractions on the genotoxicity of wastewater effluent during chlorine disinfection. Environmental Science \& Technology 41:160-165

Wang LS, Wei DB, Wei J, Hu HY (2007b) Screening and estimating of toxicity formation with photobacterium bioassay during chlorine disinfection of wastewater. J Hazard Mater 141:289-294

Watkinson AJ, Murby EJ, Costanzo SD (2007) Removal of antibiotics in conventional and advanced wastewater treatment: implications for environmental discharge and wastewater recycling. Water Res 41: $4164-4176$

Xu YG, Yu WT, Ma Q, Zhou H (2015) Occurrence of (fluoro) quinolones and (fluoro) quinolone resistance in soil receiving swine manure for 11 years. Sci Total Environ 530:191-197

Zhang HC, Huang CH (2005) Oxidative transformation of fluoroquinolone antibacterial agents and structurally related amines by manganese oxide. Environmental Science \& Technology 39:4474-4483 